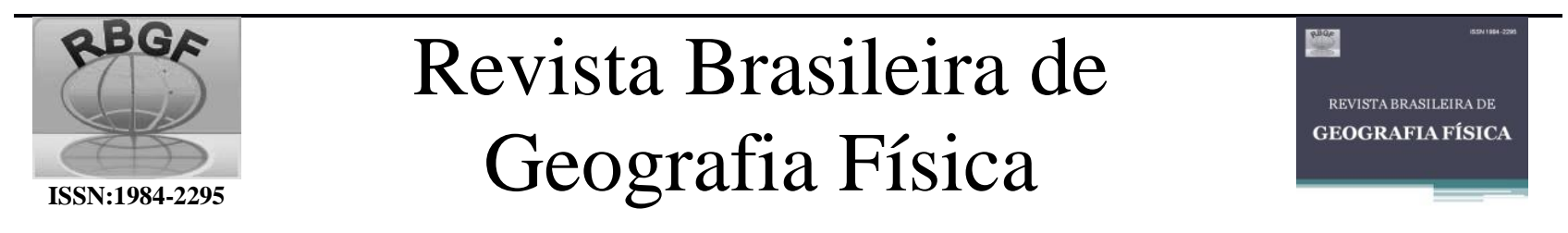

Homepage: www.ufpe.br/rbgfe

\title{
Relações entre condições ambientais e doenças de veiculação hídrica em áreas do assentamento rural Serra Grande, Vitória de Santo Antão, PE, Brasil
}

\author{
Maria Tereza Duarte Dutra ${ }^{1,}$ Juliana Lemos da Silva ${ }^{2}$, Cláudia Ricardo Oliveira ${ }^{3}$, Marília Regina Costa \\ Castro Lyra ${ }^{4}$, Suzana Maria Gico Lima Montenegro ${ }^{5}$
}

\begin{abstract}
${ }^{1}$ Professora do Curso de Tecnologia em Gestão Ambiental - Departamento Acadêmico de Ambiente, Saúde e Segurança - DASS, Instituto Federal de Educação, Ciência e Tecnologia de Pernambuco - IFPE. Recife -PE. Autor correspondente: dutra.tereza@gmail.com; ${ }^{2}$ Tecnóloga em Gestão Ambiental. jlemosj@hotmail.com; ${ }^{3}$ Discente do Departamento de Engenharia Civil, Centro de Tecnologia e Geociências da Universidade Federal de Pernambuco - UFPE. Recife - PE. cacaldeoliver@gmail.com; ${ }^{4}$ Professora do Curso de Tecnologia em Gestão Ambiental - Departamento Acadêmico de Ambiente, Saúde e Segurança - DASS, Instituto Federal de Educação, Ciência e Tecnologia de Pernambuco - IFPE. Recife - PE. marilialyra@ @ recife.ifpe.edu.br; ${ }^{5}$ Professora do Departamento de Engenharia Civil, Centro de Tecnologia e Geociências da Universidade Federal de Pernambuco - UFPE. Recife - PE. suzanam.ufpe @ gmail.com.
\end{abstract}

Artigo recebido em 07/05/2016 e aceito em 27/08/2016.

\section{R E S U M O}

A má qualidade dos corpos de água exerce influência direta sobre a saúde da sociedade, podendo causar doenças de veiculação hídrica, que levam a morte milhões de pessoas no mundo. Neste cenário, o presente estudo objetivou identificar as relações existentes entre condições ambientais e doenças de veiculação hídrica no Assentamento Rural Serra Grande, situado na sub bacia hidrográfica do Riacho Natuba, no município de Vitória de Santo Antão, em Pernambuco. Foram escolhidas seis nascentes, fazendo-se medições de parâmetros de qualidade de água, comparando-se os resultados das análises com os padrões estabelecidos pela Resolução Conama № 357/05 e Portaria do Ministério da Saúde No $2914 / 11$. Para identificar a ocorrência de doenças de veiculação hídrica no assentamento procedeu-se a aplicação de questionários junto à comunidade local, representantes do Posto de Saúde e da Secretaria de Saúde Municipal, abordando aspectos sobre a incidência dessas doenças e respectivos programas de saúde implementados. Os resultados obtidos mostraram que as nascentes representavam a principal fonte de água para o consumo doméstico, a irrigação e a dessedentação animal. No entanto, as análises de qualidade de água apontaram que a mesma não apresentava condições apropriadas ao consumo humano direto, requerendo prévio tratamento. Em relação ao perfil de ocorrência das doenças de veiculação hídrica, constatou-se que as verminoses e protozooses são as doenças que mais acometem a população.

Palavras-chave: Gestão de recursos hídricos, qualidade da água, saúde e meio ambiente.

\section{Relationships between environmental conditions and hydro term placement diseases in Rural Settlement Serra Grande, Vitória de Santo Antão, PE, Brazil}

\section{A B S T R A C T}

The poor quality of water bodies shall exercise direct influence on the health of society, causing hydro term placement diseases leading to death millions of people worldwide. In this scenario, the present study aimed to identify the relationship between environmental conditions and hydro term placement diseases in the Rural Settlement Serra Grande, located in the Sub-basin of the Natuba rivulet, in the municipality of Vitória de Santo Antão, Pernmbuco State, Brazil. Six springs were chosen for sample collections and determination of water quality parameters, comparing the results with the quality standards established by CONAMA ( Brazilian National Environmental Council) Resolution N $357 / 05$ and Ordinance of the Ministry of Health (Brazil) No. 2914/11. Questionnaires were applied to local social actors: community, health and Municipal Health Secretariat, addressing aspects of water diseases and health programs implemented. The results obtained showed that the springs were the main source of water for domestic consumption, irrigation and animal watering in the studied area. However, the water quality analyses showed that these springs do not 
show appropriate sanitary conditions to direct human consumption, requiring treatment. In relation to the profile of hydro term placement diseases occurrence, it was observed that the worms and protozooses are the diseases that most affected the local population.

Keywords: Management of water resources, quality of the water, health and environment.

\section{Introdução}

A água é um recurso natural essencial para a sobrevivência de todas as espécies que habitam a Terra, bem como para atender aos demais usos múltiplos para os quais a água é requerida. Tundisi (2003) destaca que os recursos hídricos poluídos por descargas de resíduos humanos e de animais transportam grande variedade de patógenos, entre eles bactérias, vírus, protozoários ou organismos multicelulares, que podem causar doenças gastrointestinais. Outros organismos podem infectar os seres humanos por intermédio do contato com a pele ou pela inalação por dispersão no ar, a partir de aerossóis contaminados.

Segundo Sperling (2005) a qualidade da água é resultante de fenômenos naturais e da atuação do homem. De maneira geral, pode-se dizer que a qualidade de uma determinada água é função das condições naturais e de uso e da ocupação do solo na bacia hidrográfica.

De acordo com Rodrigues e Pissara (2011), a qualidade da água sofre as consequências das atividades desenvolvidas pelo homem, e a sua qualidade resulta das influências do clima, geologia, fisiografia, solos, vegetação, e, principalmente do manejo dos sistemas produtivos agrícolas e desenvolvimento urbano. Nas áreas onde atividades antrópicas são desenvolvidas, como a agricultura, o uso do solo contribui consideravelmente nas características físicas, químicas e biológicas da água.

Segundo a Agência Nacional de Águas (ANA, 2012) o conhecimento sobre a qualidade das águas brasileiras é primordial para que seja feita sua correta gestão e para que o uso múltiplo das águas, preconizado pela Política Nacional de Recursos Hídricos (PNRH), Lei 9433 (Brasil, 1997), seja alcançado.

Neste sentido, o governo brasileiro aprovou algumas normas que estabelecem padrões de qualidade da água. A Resolução CONAMA No 357 (BRASIL, 2005), em substituição a Resolução CONAMA $\mathrm{N}^{\circ}$ 20, de 18 de junho 1986, dispõe sobre a classificação dos corpos de água e diretrizes ambientais para o seu enquadramento, bem como estabelece as condições e padrões de lançamento de efluentes, e dá outras providências.
Considerando as condições de qualidade da água para consumo humano, deve-se observar as definições da Portaria do Ministério da Saúde MS No 2914 (BRASIL, 2011), em substituição a Portaria MS No 518, de 25 de março de 2004, que dispõe sobre os procedimentos de controle e de vigilância da qualidade da água para consumo humano e seu padrão de potabilidade.

Para Brito et al. (2007), a qualidade da água é definida por sua composição e pelo conhecimento dos efeitos que seus constituintes podem causar ao ambiente, em especial à saúde do homem, sendo que os padrões de qualidade de água variam em função do seu uso.

Neste contexto, surgem as doenças de transmissão hídrica, que são aquelas em que a água atua como veículo de agentes infecciosos. Os microrganismos patogênicos atingem a água através de excretas de pessoas ou animais infectados, causando problemas principalmente no aparelho intestinal do homem. Essas doenças podem ser causadas por bactérias, fungos, vírus, protozoários e helmintos (Santos, 2006).

De acordo com Amaral et al. (2003), as doenças de veiculação hídrica, são causadas principalmente por meio de microrganismos patogênicos que têm suas origens relacionadas aos fatores espaciais do território e, são situações específicas, determinadas pelos preceitos capitalistas e dicotômicos que regem a sociedade, assumindo relevância, entre outros aspectos, na determinação de desigualdades no que tange a qualidade da água para consumo e uso humano. Segundo os mesmos autores, as doenças de veiculação hídrica, nas dimensões de incidência e prevalência causam inúmeros transtornos à saúde humana, podendo ser percebidas nos contextos patológico, social e espacial como o conjunto de fatores (materiais e imateriais) que podem interferir negativamente nas condições gerais de existência.

Segundo Daniel (2001), a prevalência das doenças de veiculação hídrica, notadamente na América Latina, África e Ásia, constitui um forte indicativo da fragilidade dos sistemas públicos de saneamento. Tal fragilidade materializa-se na ausência de redes coletoras de esgotos e, principalmente, na qualidade da água distribuída à população, quando os sistemas de abastecimento se 
fazem presentes. Esta situação ainda se faz presente em diversos municípios destes países.

Segundo a Organização das Nações Unidas (ONU, 2006), a má condição da água é fator chave para problemas de subsistência e saúde globais. Doenças relacionadas à diarreia e à malária mataram cerca de 3,1 milhões de pessoas em 2002. Noventa por cento dessas mortes foram de crianças com menos de cinco anos de idade. Aproximadamente 1,6 milhão de vidas poderiam ser salvas anualmente com o fornecimento de água potável, saneamento básico e higiene. De acordo com o UNICEF (2007), estima-se em quase dois milhões o número de crianças menores de 5 anos de idade que morrem a cada ano devido a diarreia, em todas as partes do mundo.

Kale et al. (2004) salientam que as doenças diarréicas são as principais causas de morbidades e mortalidades em crianças menores de seis anos de idade, que não estão em aleitamento exclusivo nos países em desenvolvimento, como é o caso do Brasil.

Conforme Dados da Pesquisa Nacional por Amostras de Domicílio (PNAD, IBGE, 2012) apenas 33,2 \% dos domicílios nas áreas rurais estão ligados a rede de abastecimento de água. A situação é mais crítica quando analisados dados de esgotamento sanitário, em que apenas 5,2\% dos domicílios estão ligados a rede coletora de esgotos e 28, $3 \%$ utilizam a fossa séptica como solução do tratamento, destacando-se que este cenário contribui para o surgimento de doenças de transmissão hídrica, como parasitoses intestinais e diarreias, as quais são responsáveis pela elevação da taxa de mortalidade infantil. Assim, o Ministério da Saúde, por meio da Fundação Nacional de Saúde (FUNASA), promove a implantação de ações de saneamento em áreas rurais de todos os municípios, de acordo com o que estabelece o Plano Nacional de Saúde (PNS), 2012 - 2015, com vistas a reverter este quadro (FUNASA, 2011).

Neste cenário, o presente estudo objetivou identificar as relações existentes entre condições ambientais e ocorrência de doenças de veiculação hídrica em área do Assentamento Rural Serra Grande, localizado na sub bacia do Riacho Natuba, no município de Vitória de Santo Antão, em Pernambuco, buscando contribuir com a produção de conhecimento sobre a gestão dos recursos hídricos localmente, no sentido de apoiar ações para a melhoria da qualidade da água de uso doméstico, consequentemente na prevenção de proliferação de doenças de veiculação hídrica no assentamento rural.

\section{Material e métodos}

Caracterização da Área

A pesquisa foi realizada em áreas da sub bacia do riacho Natuba, principal afluente da margem direita do Rio Tapacurá (Figura 1). A área de drenagem da sub bacia é de aproximadamente $3.874,08$ ha, correspondendo a $8,23 \%$ da área da bacia do Tapacurá, abrangendo os municípios de Vitória de Santo Antão e Pombos, localizados na Zona da Mata Centro de Pernambuco (Souza et al., 2008). A sub bacia do Natuba é divida em três partes: o Alto Natuba que possui uma área de 5,95 $\mathrm{km}^{2}$. O Médio Natuba corresponde a uma área de $23,74 \mathrm{~km}^{2}$. Já o Baixo Natuba possui área de 9,05 $\mathrm{km}^{2}$.

O clima dominante na área da bacia do riacho Natuba é o Tropical chuvoso ou Megatérmico úmido, com temperatura média anual de $23,8^{\circ} \mathrm{C}$, variando entre a mínima de $19,3^{\circ} \mathrm{C}$ e a máxima de $30,9^{\circ} \mathrm{C}$ (Silva, 2006).

De acordo com os dados pluviométricos dos postos de Vitória de Santo Antão e Engenho Serra Grande a área apresenta uma precipitação média anual entre $1.008 \mathrm{~mm}$ e $1395 \mathrm{~mm}$ com o período chuvoso entre os meses de março a julho, ou seja, chuvas de outono-inverno, concentrandose nessa estação em torno de $70 \%$ da precipitação média anual (Braga et al.,1998).

Segundo Silva et al (2001) os principais tipos de solos ocorrentes na bacia são Latossolo Amarelo, Argissolo Amarelo, Argissolo Vermelho-Amarelo, Argissolo Vermelho e Gleissolo, a bacia possui cotas altimétricas entre 150 a 590 metros havendo assim uma diferença de 440 metros entre o ponto mais alto e o mais baixo da mesma.

Ressalta-se que, a área do presente estudo representa condições típicas de várias outras localidades rurais na Zona da Mata do Nordeste de Pernambuco. 


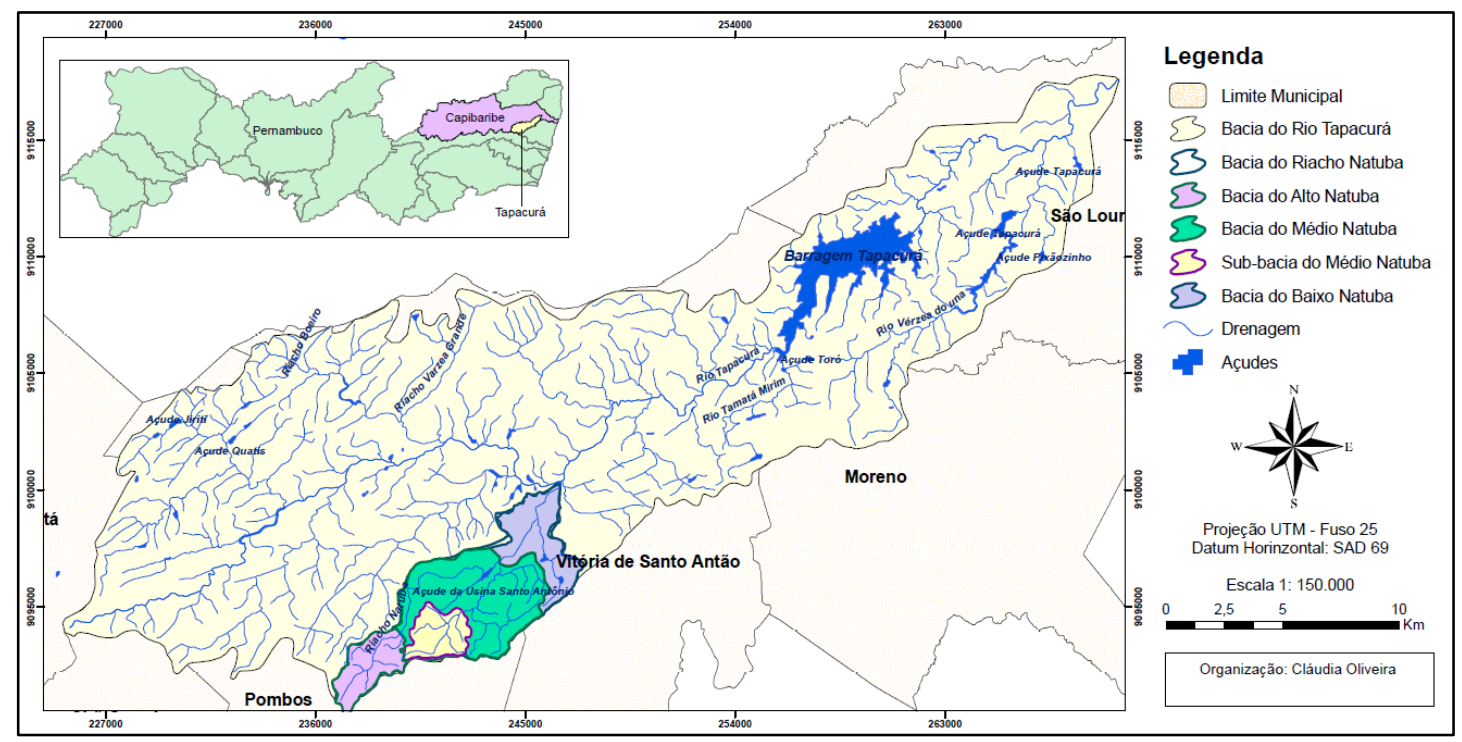

Figura 1. Localização da Sub Bacia do Natuba, com indicação da divisão nas porções alto, médio e baixo da bacia. Autoria: Claudia Oliveira, 2015.

O desenvolvimento do presente estudo, se concentrou em áreas do Assentamento Rural Serra Grande localizadas na porção média da sub bacia, considerando a participação de assentados em projeto anterior de recuperação de nascentes. Registra-se que, na área escolhida se insere equipamentos comunitários, como escola e posto de saúde.

Descrição dos métodos

Para o desenvolvimento da pesquisa, foram realizadas visitas de campo no período de outubro de 2013 a janeiro de 2014. Para escolha das nascentes utilizou-se imagem de fotogrametria aérea do ano de 2012, disponibilizada pelo Departamento de Engenharia Cartográfica da UFPE. A localização dos pontos das nascentes foi realizada com auxílio de um GPS Map 62stc de marca GARMIN.

Assim, foram escolhidas 06 (seis) nascentes para medições de parâmetros de qualidade da água, as quais foram identificadas pela numeração: $21,44.2,58,77,78.1$ e 78.2 (Figura 2). 
utilizando-se nutriente Colilert (meio de cultura),

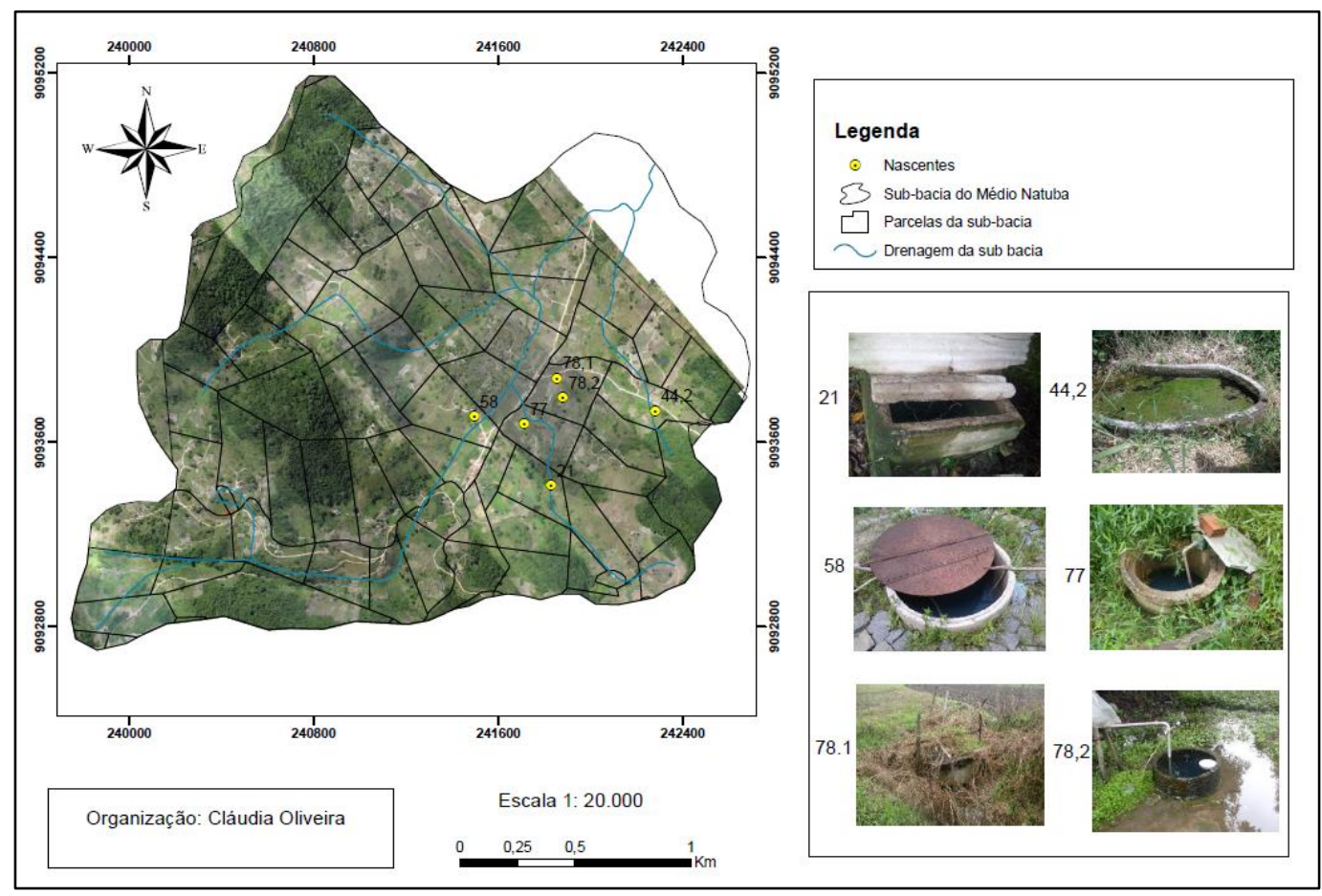

Figura 2. Localização das nascentes na Sub Bacia do Médio Natuba. Autoria: Claudia Oliveira, 2015

Análise de parâmetros de qualidade da água

Os parâmetros analisados em campo foram a T (temperatura), CE (condutividade elétrica), OD (oxigênio dissolvido) e $\mathrm{pH}$ (potencial hidrogeniônico). Também, foram coletadas amostras de água para análise dos parâmetros de Turbidez, Coliformes Totais e Escherichia Coli. As coletas de água foram feitas diretamente no corpo das nascentes, utilizando-se frascos plásticos autoclavados para a coleta. Em seguida, as mesmas foram acondicionadas em depósito de isopor com gelo e transportadas para análise de parâmetros físico e biológicos. As análises foram realizadas no Laboratório de Saneamento, do Departamento de Engenharia Civil, do Centro de Tecnologia e Geociências da UFPE.

A turbidez foi determinada pelo método Nefelométrico, em Turbidímetro Hach, modelo 2100P, as concentrações de bactérias Coliformes Totais e Escherichia Coli, foram identificadas pelo método do número mais provável (NMP), cartelas Quanti-Tray 2000, seladora Quanti-Tray, modelo 2X, estufa bacteriológica Orion, modelo 502 e lâmpada UV Spectroline, $365 \mathrm{~nm}$, modelo EA-160. Em campo, foram medidos os parâmetros para condutividade elétrica, temperatura e teor de oxigênio dissolvido, utilizando-se do aparelho multiparâmetro Hach, modelo Hq 30d flexi e o pH utilizando-se do pHametro Hanna Instruments.

A análise dos resultados para os parâmetros estudados foi realizada de acordo com limites padrões estabelecidos pela Resolução Conama No 357/05 (Quadro 1) e a Portaria do Ministério da Saúde No 2914/11 (Quadro 2), a qual se refere a potabilidade da água.

Destaca-se que no presente estudo adotouse os parâmetros indicados para a Classe 2 de acordo com a recomendação da Política Nacional de Recursos Hídricos, Lei 9433 (Brasil, 1997), uma vez que a bacia hidrográfica pesquisada não possui enquadramento dos corpos d'água. 
Revista Brasileira de Geografia Física v.09, n.06 (2016) 1677-1689.

Quadro 1. Padrões dos corpos d'água doce, de acordo com as classes da resolução CONAMA Nº 357/05

\begin{tabular}{|c|c|c|c|}
\hline \multirow[t]{2}{*}{ PARÂMETRO } & \multicolumn{3}{|c|}{ CLASSES DE ÁGUA DOCE } \\
\hline & Classe 1 & Classe 2 & Classe 3 \\
\hline OD (MG/l) & $\geq 6$ & $\geq 5$ & $\geq 4$ \\
\hline Cor $(\mathrm{uH})$ & $\leq 30$ & $\leq 75$ & $\leq 75$ \\
\hline Turbidez (NUT) & $\leq 40$ & $\leq 100$ & $\leq 100$ \\
\hline $\mathrm{PH}$ & 6 & $\mathrm{a}$ & $-\mathrm{I}$ \\
\hline $\mathrm{DBO}_{5}(\mathrm{mg} / \mathrm{l})$ & $\leq 3$ & $\leq 5$ & $\leq 10$ \\
\hline SDT (mg/l) & $\leq 500$ & $\leq 500$ & $\leq 500$ \\
\hline Coliformes totais (NMP/100ml) & 1.000 & 5.000 & 20.000 \\
\hline Coliformes termotolerantes (NMP/100ml) & $\leq 200$ & $\leq 1.000$ & $\leq 4.000^{(1)}$ \\
\hline $\mathrm{CE}(\mathrm{uS} / \mathrm{cm})$ & 10 & $\mathrm{a}$ & 100 \\
\hline
\end{tabular}

Quadro 2. Padrão microbiológico da água potável para consumo humano, de acordo com Portaria do Ministério da Saúde No 2914/11

\begin{tabular}{|c|c|c|c|c|}
\hline \multicolumn{2}{|c|}{ TIPO DE ÁGUA } & \multicolumn{2}{|c|}{ PARÂMETRO } & $\operatorname{VMP}^{(1)}$ \\
\hline \multicolumn{2}{|c|}{ Água para consumo humano } & \multicolumn{2}{|c|}{ Escherichia coli $^{(2)}$} & Ausência em 100mL \\
\hline \multirow{4}{*}{$\begin{array}{l}\text { Água } \\
\text { tratada }\end{array}$} & $\begin{array}{l}\mathrm{Na} \text { saída do } \\
\text { tratamento }\end{array}$ & Colif & mes totais ${ }^{(3)}$ & Ausência em 100mL \\
\hline & \multirow{3}{*}{$\begin{array}{l}\text { No sistema de } \\
\text { distribuição } \\
\text { (reservatórios e rede) }\end{array}$} & \multicolumn{2}{|c|}{ Escherichia coli } & Ausência em $100 \mathrm{~mL}$ \\
\hline & & \multirow[t]{2}{*}{$\begin{array}{l}\text { Coliformes } \\
\text { totais }(4)\end{array}$} & $\begin{array}{l}\text { Sistemas ou } \\
\text { soluções coletivas } \\
\text { que abastecem } \\
\text { menos de } 20.000 \\
\text { habitantes }\end{array}$ & $\begin{array}{l}\text { Apenas uma amostra, entre as } \\
\text { amostras examinadas no mês, } \\
\text { poderá apresentar resultado } \\
\text { positivo }\end{array}$ \\
\hline & & & $\begin{array}{lr}\text { Sistemas } & \text { ou } \\
\text { soluções } & \\
\text { alternativas } & \\
\text { coletivas } & \text { que } \\
\text { abastecem a partir } \\
\text { de } & 20.000 \\
\text { habitantes } & \end{array}$ & $\begin{array}{l}\text { Ausência em } 100 \mathrm{~mL} \text { em } 95 \% \\
\text { das amostras examinadas no } \\
\text { mês }\end{array}$ \\
\hline
\end{tabular}

Levantamento de doenças de veiculação hídrica

Para o levantamento da ocorrência de doenças de veiculação hídrica, foram aplicados questionários junto a 14 famílias moradoras da vila rural do assentamento Serra Grande, que são abastecidas pelas nascentes escolhidas, abordando os seguintes aspectos: origem da fonte de abastecimento de água, tipo de tratamento da água antes do consumo, finalidade de uso da água, e conhecimento sobre quais doenças são transmitidas ao homem pela água contaminada.

Ainda, foi aplicado questionário ao Posto de Saúde da Família (PSF), tendo sido respondido pela enfermeira responsável pela Estratégia de
Saúde da Família (ESF com relação a ocorrência das doenças de veiculação hídrica, levantando quais as causas mais frequentes de contaminação da água para consumo, quais os sintomas causados e qual faixa etária é mais afetada.

Identificação de programas e ações de controle das doenças de veiculação hídrica

O questionário direcionado ao Posto de Saúde também investigou quais os tratamentos utilizados para tais doenças, quem é responsável pela vigilância das doenças no assentamento, atuação dos agentes de saúde, se existe alguma doença que teve redução drástica de incidência e 
como é feita a promoção de medidas de controle adotadas e as formas de prevenção de doenças.

Também foi aplicado questionário junto a Secretaria de Saúde do Município da Vitória de Santo Antão, na pessoa do Coordenador Geral de Vigilância em Saúde, pautando-se nos aspectos relacionados a disponibilidade de infraestrutura física e de pessoal, serviços oferecidos e programas voltados à questão do saneamento básico, da saúde e da educação.

\section{Resultados e discussão}

A partir da análise dos resultados obtidos, foi possível caracterizar a forma de uso, tratamento e acesso à água por parte das famílias assentadas, no intuito de estabelecer as relações entre condições ambientais e ocorrência de doenças de veiculação hídrica em área do Assentamento Rural Serra Grande, em Vitória de Santo Antão, Pernambuco.

Neste sentido, destaca-se que, a principal fonte de água para abastecimento das famílias assentadas entrevistadas, é proveniente diretamente das nascentes, corroborando com as referências consultadas na pesquisa.

Usos múltiplos da água

Constatou-se que os principais tipos de uso da água são: consumo doméstico (beber, cozinhar, tomar banho, lavar roupa), irrigação de culturas (hortaliças, macaxeira, limão, batata doce, quiabo, banana) e a dessedentação de animais (porcos, galinhas, vacas, cachorro, perus e gatos).

Quanto à forma de captação da água para o abastecimento das famílias, observou-se o uso de técnicas por gravidade (64\%), bombeamento $(29 \%)$ ou coleta manual direto da fonte (7\%). Já, o armazenamento da água nas casas era feito em caixas d'água pela maioria das famílias (64\%), podendo ser armazenada em baldes ou recipientes plásticos (36\%), muito destes improvisados (Figura 3).

Destaca-se que no tratamento prévio da água para consumo humano, era utilizada solução de hipoclorito (56\%), distribuída pelos agentes de saúde, em suas visitas periódicas aos assentados, além de alguns filtrarem (33\%) e/ou ferverem $(11 \%)$ a água.

Ainda, registrou-se que, $93 \%$ das famílias entrevistadas consomem diretamente água das nascentes e apenas $7 \%$ destas, consomem água mineral.

Com relação à percepção da população em relação a qualidade de água das nascentes, perguntou-se aos assentados o que eles acharam da água que consumiam, ao que responderam que consideravam a água boa (61\%), ótima (31\%) e ruim $(8 \%)$.
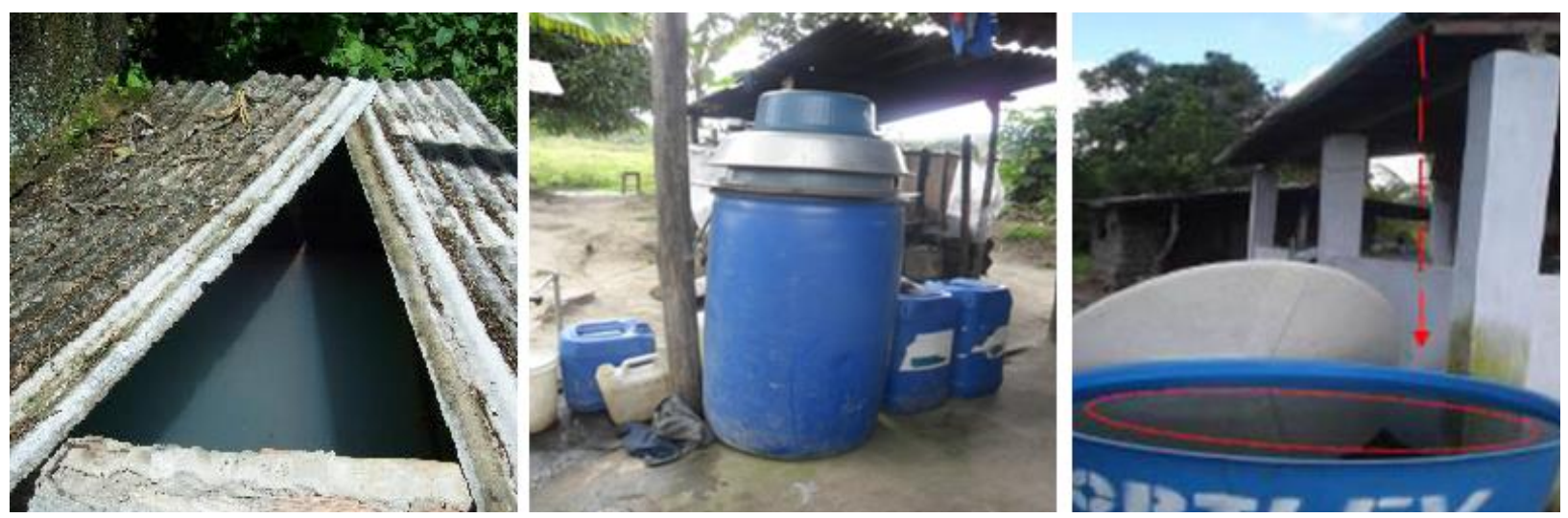

Figura 3. Tipos de armazenamento de água em áreas do Assentamento Rural Serra Grande, município de Vitória de Santo Antão - PE. Autoria: Juliana Lemos da Silva e Cláudia Oliveira, 2013

Análise da qualidade de água

Os resultados das análises de água das nascentes, quando comparados com os padrões da Resolução Conama N $N^{\circ} 357 / 05$ e Portaria do Ministério da Saúde $N^{\circ}$ 2914/11, apresentam algumas situações que merecem atenção dos órgãos gestores, no sentido de monitorá-las qualitativamente. Os resultados das análises de água realizadas em 6 (seis) nascentes do assentamento, quanto aos parâmetros físicos, químicos e biológicos para o período seco, podem ser observados na Tabela 1. 
Tabela 1. Parâmetros analisados para identificação da qualidade de água de nascentes em áreas do Assentamento Rural Serra Grande, em Vitória de Santo Antão, Pernambuco, 19 de dezembro de 2013

\begin{tabular}{cccccccc}
\hline $\begin{array}{c}\text { IDENTIFICAÇÃO } \\
\begin{array}{c}\text { DAS } \\
\text { NASCENTES }\end{array}\end{array}$ & \multicolumn{2}{c}{ FÍSICO } & \multicolumn{3}{c}{$\begin{array}{c}\text { PARÂMETROS } \\
\text { QUÍMICO }\end{array}$} \\
\hline & $\mathrm{T}^{\circ} \mathrm{C}$ & $\begin{array}{c}\mathrm{T} \\
(\mathrm{UNT})\end{array}$ & $\begin{array}{c}\mathrm{CE} \\
(\mu 5 / \mathrm{cm})\end{array}$ & $\begin{array}{c}\text { OD } \\
(\mathrm{mg} / \mathrm{l})\end{array}$ & $\begin{array}{c}\mathrm{pH} \\
(0-9)\end{array}$ & $\begin{array}{c}\text { Coli Totais } \\
(\mathrm{NMP} / 100 \mathrm{ml})\end{array}$ & $\begin{array}{c}\text { E. Coli } \\
(\mathrm{NMT} / 100 \mathrm{ml})\end{array}$ \\
\hline N.21 & 26,3 & 5,4 & 339 & 0,88 & 5,70 & 101,2 & 755,6 \\
N.44.2 & 26,5 & 1,94 & 102,1 & 8,52 & 5,40 & 1011,2 & 238,2 \\
N.55 & 25,7 & 17,34 & 144,3 & 2,62 & 5,11 & 1011,2 & $<1$ \\
N.77 & 26,3 & 5,40 & 339 & 0,88 & 5,70 & 1011,2 & 755,65 \\
N.78.1 & 25,0 & 11,45 & 194,9 & 6,88 & 7,00 & 1011 & 38,8 \\
N.78.2 & 28,0 & 7,69 & 132,4 & 3,08 & 5,06 & 1011,2 & 10,9 \\
\hline
\end{tabular}

Diante dos dados obtidos para o parâmetro turbidez (T), pode-se destacar que, de acordo com a Resolução Conama No 357/05 para classe 2, todas as nascentes atenderam ao padrão estabelecido. Porém, quando comparou-se a turbidez pelo padrão da Portaria do Ministério da Saúde No 2014/11, nenhuma das nascentes atenderam ao limite maioria das nascentes se encontrarem expostas, com ocorrência de material particulado em suspensão, não sendo adequada para consumo humano, devendo-se assim, aplicar medidas de tratamento prévio da água, como a filtragem e uso de solução de hipoclorito. estabelecido (Figura 4), possivelmente devido a

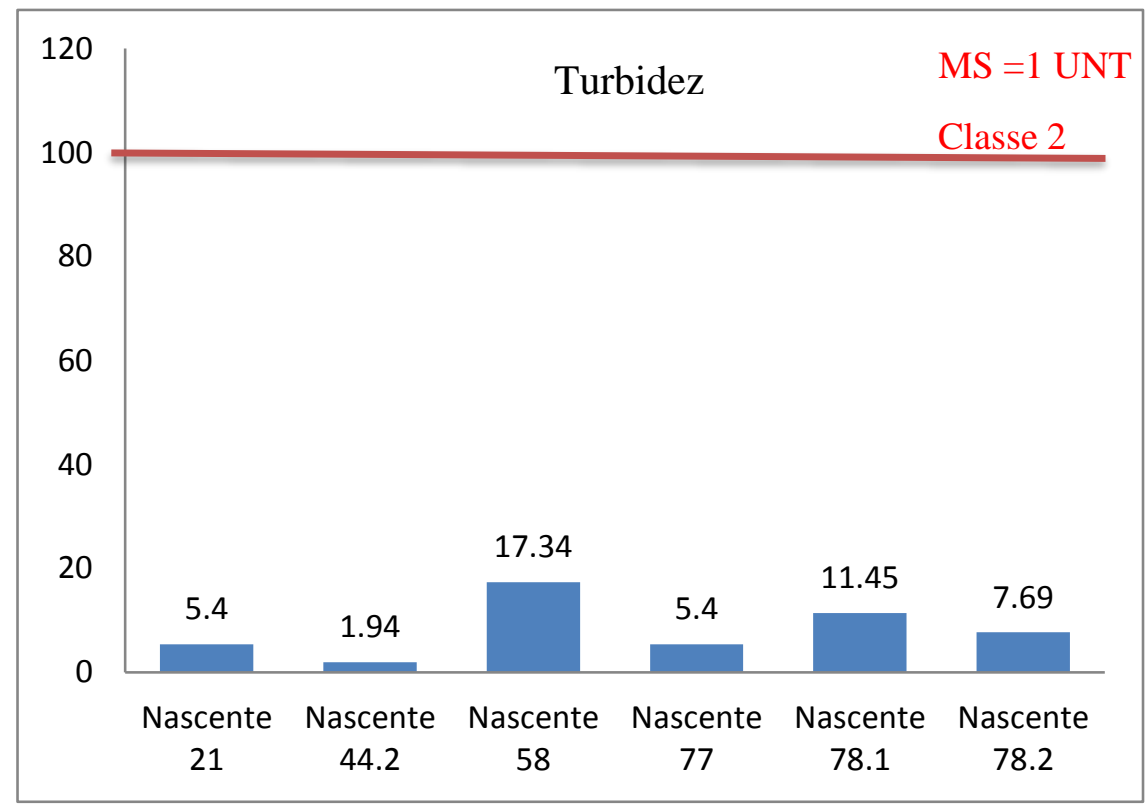

Figura 4. Comportamento do parâmetro turbidez em relação à classe 2, conforme Resolução CONAMA No 357/05 e referenciais da Portaria No 2914/11 do Ministério da Saúde

Em relação ao parâmetro oxigênio dissolvido (OD), as nascentes 44.2 e 78.1 atenderam ao padrão de qualidade estabelecido pela Resolução CONAMA No 357/05 para classe 2. Quanto ao Ministério da Saúde, esse não estabelece limites para esse parâmetro (Figura 5). 


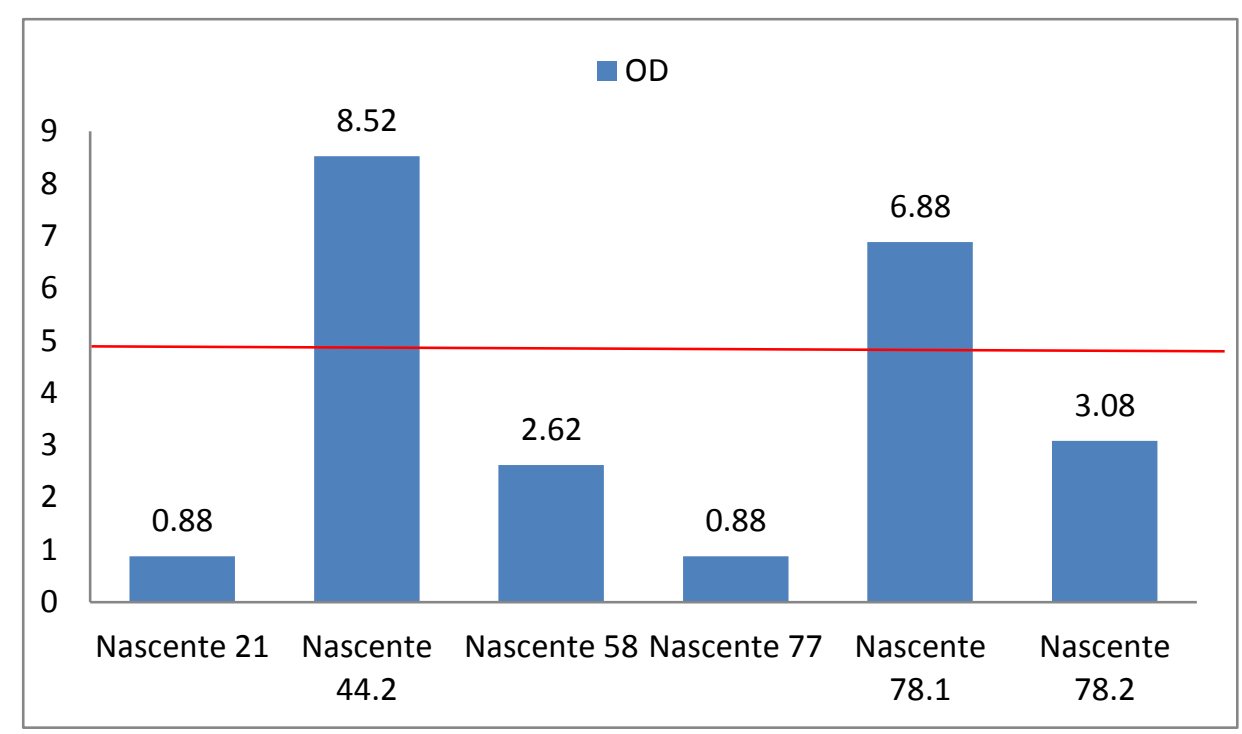

Figura 5. Comportamento do parâmetro oxigênio dissolvido em relação à classe 2, conforme Resolução

Para o parâmetro físico-químico $\mathrm{pH}$, verificou-se que não ocorreram grandes variações, todas as nascentes estudadas tiveram o seu $\mathrm{pH}$ iando entre 5.4 a 7,0 muito próximo do valor mínimo estabelecido $(6,0)$ exigido pela resolução Conama 357/05 para classe 2 e pela Portaria do Ministério da Saúde 2914/11.
Quanto aos parâmetros microbiológicos, Coliformes Totais e Escherichia Coli, foi constatado que para os Coliformes Totais, apenas a nascente 21 atendeu ao apontado pela Resolução Conama $\mathrm{N}^{\mathrm{o}}$ 357/05 de até $1000 \mathrm{NMP}$ em $100 \mathrm{ml}$, destacando-se assim, a necessidade de um tratamento prévio da água das nascentes utilizadas para consumo doméstico (Figura 6).

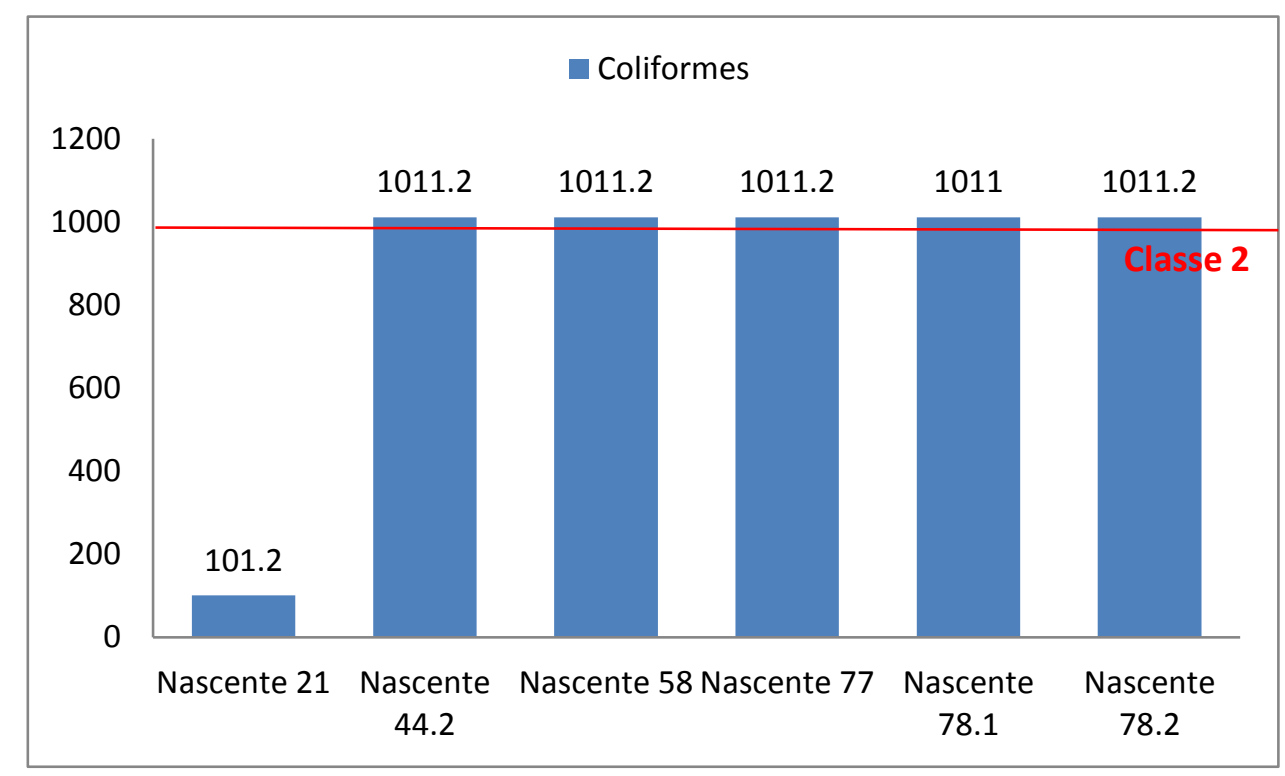

Figura 6. Comportamento do parâmetro Coliformes Totais em relação à classe 2, conforme Resolução CONAMA No 357/05 e Ministério da Saúde No 2914/11. 
Foi verificado também que, para Echerichia Coli, a nascente 58 atende aos padrões $(<1 \mathrm{NMP} / 100 \mathrm{ml})$ estabelecidos pela Portaria do Ministério da Saúde No 2914/11. Já as nascentes 21, 44.2, 77, 78.1 e 78.2 não atendem aos padrões (entre 10,9 e 755,6 NMP/100 ml), indicando presença das bactérias advindas de fezes humanas e de animais sendo assim consideradas impróprias para consumo. Com relação a Resolução Conama $\mathrm{N}^{\circ} 357 / 05$, que estabelece até $1000 \mathrm{NMP}$, todas as nascentes atenderam ao padrão exigido, para os demais usos que não a ingestão (Figura 7).

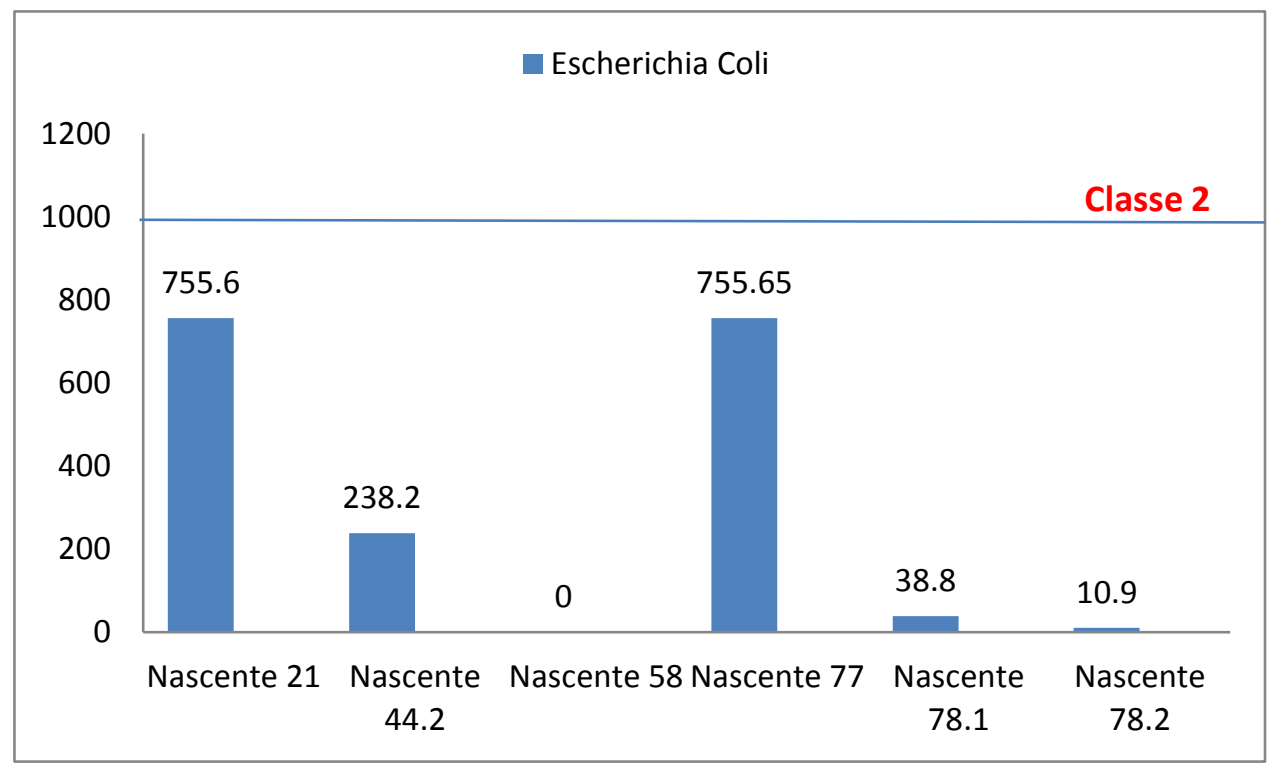

Figura 7. Comportamento do parâmetro Escherichia Coli em relação a classe 2, pela Resolução CONAMA N ${ }^{\circ}$ 357/05 e Ministério da Saúde No 2914/11

Diante dos resultados de análise de qualidade de água, para o período estudado, destaca-se a importância de ações de sensibilização junto a população para a importância do prévio tratamento da água para consumo. Registra-se que o Posto de Saúde distribui e orienta quanto ao uso de hipoclorito de sódio, como forma de tratamento prévio da água para consumo humano. Neste sentido, algumas das famílias entrevistadas, informaram a respeito do uso deste produto no seu dia a dia.

Mattos (2004) afirma que, tendo em vista que a população de assentamento rural não possui acesso a água de qualidade para consumo, uma das alternativas de tratamento dessa água seria através do uso de hipoclorito de sódio. No entanto, no seu estudo em agrovilas no município de Promissão, em São Paulo, ele verificou que esse procedimento não está sendo realizado pela maioria das agrovilas, apesar dos moradores possuírem acesso ao hipoclorito no posto de saúde, Deste modo, foi possível detectar a necessidade de se elaborar propostas educativas relativas ao tratamento da água para próprio benefício da saúde da população.

Também, de igual importância, é a necessidade de intervenção dos governantes para atendimento dos serviços básicos de saneamento no Assentamento Rural Serra Grande.

Ocorrência de doenças de veiculação hídrica

A percepção das famílias dos assentados, em relação à ocorrência de doenças de veiculação hídrica apontou que 93\% dos entrevistados já ouviram falar das doenças de veiculação hídrica, e apenas $7 \%$ responderam que não ouviram falar sobre essas doenças.

Também foram questionados sobre quais são as doenças que a água contaminada pode transmitir ao homem, tendo a maioria das respostas apontou as verminoses (32\%), além da dengue 
(29\%), esquistossomose (16\%), hepatite (13\%) e não souberam responder (10\%).

Quando questionados sobre alguns sintomas relacionados a doenças de veiculação hídrica como: diarréia, vômito, dor abdominal, febre, dor de cabeça e tonturas, a maior parte dos entrevistados responderam que a dor abdominal é um dos sintomas mais frequentes entre eles.

Os sintomas causados pelas doenças de veiculação hídrica, a exemplo dos que foram informados pelos assentados, podem ser melhor identificados no Quadro 3.

Quadro 3. Doenças transmitidas pela água poluída e contaminada

\begin{tabular}{|c|c|c|c|}
\hline DOENÇA & $\begin{array}{c}\text { AGENTE } \\
\text { INFECCIOSO }\end{array}$ & $\begin{array}{l}\text { TIPO DE ORGANISMO } \\
\text { QUE CAUSA DOENÇA }\end{array}$ & SINTOMAS \\
\hline Cólera & Vibrio cholerae & Bactéria & - Diarréia severa; vômitos; perda de líquidos. \\
\hline Desinteria & Shigella dysinteriae & Bactéria & $\begin{array}{l}\text { - Infecção do cólon, diarreia e perda de sangue, } \\
\text { dores abdominais intensas. }\end{array}$ \\
\hline $\begin{array}{l}\text { Hepatite } \\
\text { infecciosa }\end{array}$ & Vírus da hepatite A & Vírus & $\begin{array}{l}\text { - Inflamação do fígado, causando vômitos, } \\
\text { febre e náuseas ; perda de apetite. }\end{array}$ \\
\hline $\begin{array}{l}\text { Desinteria } \\
\text { anabiana }\end{array}$ & Entamoeba histolytica & Protozoário & $\begin{array}{l}\text { - Infecção no cólon que causa diarreia, perda de } \\
\text { sangue e dores abdominais. }\end{array}$ \\
\hline Esquitossomose & Schistossoma sp. & Verme & $\begin{array}{l}\text { - Doença tropical que ataca o fígado, causa } \\
\text { diarreia, fraqueza e dores abdominais. }\end{array}$ \\
\hline Ancilostomíase & Ancylostoma sp. & Verme & -Anemias, sintomas de bronquite. \\
\hline Malária & $\begin{array}{l}\text { Anopheles } \\
\text { (Transmissor) }\end{array}$ & Protozoário & - Febre alta, prostação. \\
\hline Dengue & $\begin{array}{l}\text { Aedes } \\
\text { (Transmissor) }\end{array}$ & Vírus & - Anemia. \\
\hline $\begin{array}{l}\text { Criptos } \\
\text { oridiose }\end{array}$ & Cryptosparodium sp. & Protozoário & $\begin{array}{l}\text { - Diarréia e dores que podem durar mais de } \\
\text { vinte dias. }\end{array}$ \\
\hline
\end{tabular}

Fonte: Adaptado de Rebouças (2006).

A percepção dos assentados quanto a ocorrência de doenças de veiculação hídrica foi confirmada segundo informações do Posto de

Saúde da Família - PSF, pois de acordo com esta fonte, as verminoses, a exemplo da esquistossomose, são as doenças de veiculação hídrica que mais afetam esta população.

Segundo Almeida (2013), de acordo com pesquisa realizada em assentamentos no Mato Grosso, constatou o hábito disseminado entre os agricultores familiares em se consumir água em estado natural, sem nenhum tratamento, o que ocorre pelo fato de se acreditar que as águas subterrâneas não apresentam nenhum tipo de contaminação, por passarem por um processo de filtragem natural (percolação).

De acordo com informações do PSF, as doenças de veiculação hídrica são tratadas mediante exames e medicamentos. Entre os sintomas mais observados nos pacientes contaminados, o mais comum são as dores abdominais que afetam crianças de 1 a 7 anos de idade e os adultos de um modo geral. A vigilância das doenças de veiculação hídrica é feita por agentes comunitários, enfermeira, médico e técnicos de equipe de saúde. Ainda, segundo informações fornecidas pelo PSF, já existiu surto de doenças relacionadas a ingestão de água contaminada, dentre elas: amebíase, giardíase, ascaridíase e esquistossomose.

Este quadro de ocorrência de doenças de veiculação hídrica, em particular em relação a esquistossomose é corroborado pelo Ministério da Saúde (2006), quando afirma que as prevalências mais altas são encontradas em localidades dos municípios das bacias do Capibaribe, Una, Serinhaém, Ipojuca, Jaboatão e Goiana.

É importante ressaltar que, a área do assentamento é considerada de risco por não ter saneamento básico, registrando-se, em geral, ocorrência de fossas sépticas.

Desta forma, o saneamento ambiental se apresenta como meio para se atingir níveis de salubridade para proteger e melhorar as condições de vida das populações urbanas e rurais. Este inclui o abastecimento d'água potável, coleta e disposição sanitária dos resíduos líquidos e sólidos, uso e ocupação adequada do solo, drenagem, 
controle de vetores e reservatórios de doenças transmissíveis (MS, 2014).

Implementação de programas e ações de controle das doenças de veiculação hídrica

Destaca-se, que os agentes de saúde são a grande fonte de informação na área de saúde, responsável por todas as atividades realizadas no assentamento. Além das visitas domiciliares, realizam palestras na unidade de saúde, medidas antropométricas, acompanhamento de gestantes, hipertensos, diabéticos, crianças, idosos, apoio a campanha de vacinação, controle e prevenção de doenças.

O Assentamento Serra Grande conta com uma equipe de Programa de Saúde composta por agentes comunitários de saúde, enfermeira, médico, técnica. Para o diagnóstico das doenças são realizados exames, como hemograma completo para verificação de sinais de anemia, teste de anticorpos para verificar sinais de infecção e por meio da verificação de sintomas característicos. Ainda, como infraestrutura comunitária local, a população do Assentamento Rural Serra Grande é atendida por uma Escola Municipal.

Realizou-se entrevista junto a Secretaria de Saúde do Município da Vitória de Santo Antão para identificação de sua infraestrutura na área de saúde, a qual oferece os serviços de promoção e prevenção em saúde, serviços de atendimento médico e de enfermagem e serviços de diagnóstico e reabilitação, desenvolvendo os seguintes programas: Programa de Saúde da Família; Núcleo de apoio a saúde da família; Programa de Controle da Dengue, Esquistossomose, Doença de Chagas e da Raiva Animal; Programa de Tuberculose e Hanseníase; Programa das Doenças Sexualmente Transmissíveis e AIDS; Programa Academia da Saúde; Programa de Tabagismo. Ainda, foi possível registrar que as ações na área de saúde são comuns em áreas urbanas e rurais.

\section{Conclusões}

Diante dos resultados obtidos para a área do Assentamento Rural Serra Grande, em Vitória de Santo antão-PE, para o período estudado, podese inferir que:

1. As nascentes são a principal fonte de abastecimento de água da população do assentamento rural, sendo que, os principais usos da água, consistem nas atividades domésticas, dessedentação de animais e irrigação, sendo esta a principal atividade econômica da população.
2. Apesar das ações realizadas pelos Agentes Municipais de Saúde sobre as formas de tratamento de água domiciliar, essas práticas precisam ser incorporadas de forma melhor pela população, uma vez que, algumas famílias não utilizam o produto hipoclorito fornecido, e também, poucos filtram ou fervem a água, isto por que, algumas famílias continuam confiando na qualidade da água das nascentes para consumo in natura.

3. Quanto à percepção sobre os aspectos de ocorrência das doenças de veiculação hídrica, o estudo revelou que 93\% dos entrevistados conhecem as doenças de veiculação hídrica.

4. Os resultados obtidos sobre a qualidade da água, apontaram o não atendimento aos padrões de Turbidez, pH e Escherichia Coli, para algumas das nascentes de acordo com a Portaria MS $\mathrm{N}^{\circ}$ 2914/11. Já os padrões de Coliformes Totais, Oxigênio dissolvido e $\mathrm{pH}$ obtiveram resultados em algumas nascentes que atenderam aos padrões da Resolução Conama No 357/05.

5. A precariedade da infraestrutura relativa ao saneamento básico, pois o assentamento não possui serviço público de abastecimento de água e coleta/tratamento de esgoto (as casas possuem fossas sépticas) e nem coleta de lixo, bem como a falta de proteção física das nascentes, podem ser apontadas como potenciais causas de risco de contaminação das fontes de recursos hídricos locais.

6. Faz-se necessário se intensificar as campanhas educativas de sensibilização dos assentados, seja no Posto de Saúde, como também na Escola do Assentamento Rural, no sentido de mobilizar os estudantes para a adoção de práticas adequadas para o tratamento da água, em especial a água destinada ao consumo humano, os quais poderiam vir a atuar como agentes multiplicadores dos principais cuidados de higiene com a água consumida nas casas, junto a seus pais, contribuindo para a prevenção da ocorrência de doenças de veiculação hídrica.

\section{Agradecimentos}

Os autores agradecem o apoio logístico do IFPE nas campanhas de campo. Ao Laboratório de Saneamento Ambiental da UFPE pelo suporte nas análises de qualidade de água. Aos assentados, aos técnicos do Posto de Saúde do Assentamento Rural de Serra Grande e a Secretária de Saúde de Vitória de Santão Antão pela presteza em compartilhar informações. 


\section{Referências}

Almeida, J. L., Faria, A.M.M., Dallemole, D., 2013. Desenvolvimento socioambiental e passivo hídrico em projetos de assentamentos de Mato Grosso. Sociedade e Desenvolvimento Rural, 7, $44-61$.

ANA. Agência Nacional das Águas. 2012.. Panorama de qualidade das águas superficiais do Brasil, Disponível: http://arquivos.ana.gov.br/imprensa/publicac oes/Panorama_Qualidade_Aguas_Superficiai s_BR. Acesso em 16 ago. 2013.

Amaral, L. A., Nader Filho, A., Rossi Junior, O. D., Ferreira, F. L. A., Barros, L. S. S., 2003. Água de consumo humano como fator de risco a saúde em propriedades rurais. Revista de Saúde Pública 37, 510 - 514. Disponível: http://dx.doi.org/10.1590/S003489102003000400017. Acesso: 25 Set. 2013.

BRASIL, 2005. Conselho Nacional do Meio Ambiente - CONAMA. Resolução no 357 , de 17 de março.

BRASIL. 2011. Ministério da Saúde - MS. Portaria $\mathrm{N}^{\circ} 2914$, de 12 de dezembro.

BRASIL. 1997. Lei 9433, de 8 de janeiro.

Brito, L. T. de L.; Amorim, M. C.; Leite, W. de M. 2007. Qualidade de água para consumo humano. Petrolina: Embrapa Semi-Árido. Documentos, 196. 16 p.

Daniel, L. A. (Coord.) 2001. Processos de desinfecção e desinfetantes alternativos na produção de água potável. São Paulo: Projeto PROSAB. ABES. $1^{a}$ edição. 149 p.

Fundação Nacional de Saúde (FUNASA). 2011. Saneamento rural. Brasilia: Ministério da Saúde. 12 p.

Kale, P.L., Fernandes, C., Nobre, F.F., 2004. Padrão temporal de internações e óbitos por diarréia em crianças, 1995 a 1998, Rio de Janeiro. Revista de Saúde Pública [online] 38, 30 - 37. Disponível:

http://dx.doi.org/10.1590/S003489102004000100005. Acesso: 22 Out. 2013.

Mattos, N. S. de; Soares, F. M. P. 2004. Análise Microbiológica da água do assentamento rural de Promissão. Pública 38, 571-577.

Ministério da Saúde (MS). 2006. Secretaria de Vigilância em Saúde. Sistema nacional de vigilância em saúde: relatório de situação: Pernambuco / Ministério da Saúde, Secretaria de Vigilância em Saúde. - 2. ed. - Brasília. 24 p. : il.

Ministério da Saúde (MS). 2014 (a). Engenharia da Saúde Pública. Saneamento Rural.
Disponível:

http://www.funasa.gov.br/site/engenharia-desaude-publica-2/saneamentorural/\#prettyPhoto. Acesso: 03 de nov.

Ministério da Saúde (MS). 2014 (b). Secretaria de Vigilância em Saúde. Departamento de Vigilância Epidemiológica. Vigilância da Esquistossomose Mansoni: diretrizes técnicas / Ministério da Saúde, Secretaria de Vigilância em Saúde, Departamento de Vigilância das Doenças Transmissíveis. - 4. ed. - Brasília: Ministério da Saúde, 144 p. : il

ONU. Organização das Nações Unidas. 2013. Segundo relatório sobre o desenvolvimento dos recursos hídricos no mundo, 2006. Disponível:

http://www.eco21.com.br/textos/textos.asp?I $\mathrm{D}=1306$. Acesso: 25 Ago. 2013

Rebouças, A. da C.; Braga, B.; Tundisi, J. G. 2006. Águas doces no Brasil: Capital ecológico, uso e conservação. $3^{\mathrm{a}}$ ed, São Paulo, Escrituras Editora.

Rodrigues, F. M.; Pissarra, T. C. T.; Campos, S. 2011. Análise de fósforo no recurso hídrico da microbacia hidrográfica da Fazenda Glória, Taquaritinga, SP. Revista Sodebras [online] 6, $1 \quad-\quad 8 . \quad$ Disponível: http://www.sodebras.com.br/edicoes/N61.pdf . Acesso: 25 Abr. 2016.

Santos, L. A. dos. 2006. A falta de saneamento é o principal responsável pelos índices de Doença de Veiculação Hídrica? Um estudo das populações que habitam as margens de igarapés em Manaus, - AM. Dissertação. (Mestrado em Ciências do Ambiente Sustentabilidade na Amazônia). Universidade Federal do Amazonas. Amazonas. 104 p.

Souza, S. F. de, Araújo, M. do S. B. de, Braga, R. A. P., Silva, C. E. M. da 2008. Características fisiográfica da sub-bacia do rio Natuba-PE. Revista Brasileira de Geografia Física 1, 1 14.

Sperling. M. V. 2005. Introdução à qualidade das águas e ao tratamento de esgotos. Belo Horizonte: Departamento de Engenharia Sanitária e Ambiental. Universidade Federal de Minas Gerais. 3.ed. 452 p.

Tundisi. J. G. 2003. O futuro dos recursos. Instituto Internacional de Ecologia. São Paulo-SP.

UNICEF. United Nations International Children's Emergency Fund. 2007. Situação mundial da infância: sobrevivência infantil. Disponível: http://www.unicef.org/brazil/pt/sowc2008_br .pdf. Acesso: 05 Out. 2013 
Revista Brasileira de Geografia Física v.09, n.06 (2016) 1677-1689. 